the animals used, man himself, meaning nearly always the investigator, has a prominent place in this book, which is as worthy a way of paying tribute to our great men as we could wish for. The author has drawn freely on articles appearing in Conquest, the journal of the Research Defence Society, over the past ten years.

A former university lecturer who has written a standard work on parasitology might be expected to have written in the style of a text-book; but Dr. Lapage has avoided this pitfall, without sacrificing accuracy and extensive documentation. The book is outstandingly readable; yet it includes nine pages of bibliography and a further nine of index.

There is so much to applaud in this dispassionate treatment of an emotive subject that even to guggest imperfections might be thought ungracious. The emphasis on infectious diseases-three chapters out of ten-is easily defended, for they represent medicine's greatest achievements to-day. Chemotherapy, hormones, nutrition and deficiency diseases are, inter alia, also well treated. The absence of a foreword is regretted, all the more because the preface is so short. I discovered only two misprints.

The wise refusal of the author to discuss the moral question is the best reason of all why this book should be compulsory reading for all who recognizo that, in animal experimentation, a moral question exists.

The presentation conforms to the high standard one has come to expect from the publishers.

W. Lane-Petter

\section{SCIENCE FOR THE FAMILY}

Science

Chemistry, Physics, Astronomy. Editorial Board: Dr. J. Bronowski, with Sir Gerald Barry, James Fisher, and Sir Julian Huxley. (The Macdonald Illustrated Library.) Pp. 367. (London: Macdonald and Co. (Publishers), Ltd., 1960.) 45s. net.

$\mathrm{T}$ HIS is the first volume of a library of knowledge written for young readers and their parents. The book is so arranged that each double page forms a separate article. This arrangement has distinct advantages over an alphabetical one, and considerable care and thought have been taken in planning the order of the articles so that the book presents a coherent whole. There are a comprehensive glossary as well as an index. In addition, several useful references occur incidentally in the list of illustration credits ; but, in a book where much of the information is of necessity superficial, a more systematic bibliography would surely have been welcomed by many readers.

The text is copiously illustrated with excellent diagrams, prints and photographs, containing information complementary to that of the text. There are also several full-page illustrations in colour by Hans Erni which, while being delightful and of high artistic merit, seem unlikely to aid the young reader in his understanding of the subject-matter.

The book unfolds the story of the advancement of the physical sciences from very early times up to the present day, including topics such as polymers, atomic power, television and satellites. A judicious and comprehensive selection has been made, and wisely no attempt has been made to introduce subjects which could not be explained adequately in elementary terms. There is a commendable lightness of touch (not always to be found in works of an encyclopredic nature) in the text, though occasional lapses do occur. For example, we aro told on p. 126 that "work is done only when the force acting on a body moves that body in the direction of the force". On p. 128 the reader is apparently encouraged to use "weight" as synonymous with "mass". It is stated on p. 232 that, for a convex lens, "nearer the center ... the rays are bent less sharply" and on p. 233, for the same lens, that "the lens bends rays that pass near" its center more than rays that pass near its edge". The machine shown on p. 121 has mechanical advantage 3, and not 4 as stated. Very few misprints were detected, but the young British reader needs warning that, the book being "international in scope", an American system of spelling has, perhaps unfortunately, been adopted.

These are only minor criticisms. The distinguished oditorial board, and all others concerned in its production, are to be complimented on a volume of high quality which will undoubtedly give hours of enjoyment to many readers both young and old. It would suroly prove a popular addition to any school library.

D. R. Dickinson

\section{THE HIDDEN MIND}

The Wish to Fall III

A Study of Psychoanalysis and Medicine. By Karin Stephen. Pp. vi +238. (Cambridge: At the University Press, 1960.) 10s. 6d. net; 1.45 dollars, paper bound.

THIS book is an excellent introduction to psychoanalytical theory. It has been based on lectures given to medical students at the University of Cambridge and so is comprehensible to those who have little or no psychiatric knowlodge. The author draws on her clinical experience and the cases she quotes add interest to the theoretical descriptions.

Dr. Stephen commences with a discussion of the origin of the unconscious in disappointment, conflict and repression, and describes how this is solved by illness. She shows the obstacles in the way of investigating the unconscious and how psychoanalytical technique uses free association to penetrate this barrier.

Having shown the difficulties to investigation she passes on to describe what is found once we are able to lift the lid of the mind, as it wore, and see what is underneath: the primitive sexual nature of the unconscious, infantile pleasure-seeking by mouth, excretory pleasuro-seeking and phallic-ploasure seeking.

This naturally leads on to the fears of being deprived of such enjoyment-to the Oedipus complex and castration fears; the arousal of anxiety and guilt, and defonce mechanisms; finally, the use of transference in treatment.

Many poople, even now, have little or no idea what the analyst is trying to do or how he produces cures. Properly conducted analysis is much more scientific than is often appreciated and the process is more related to observing any other natural phenomena than to patting someone's hand and telling him all is well-which is the popular idea of the process.

Clifford Allen 